\title{
Preface to the special issue "High-definition topographic and geophysical data in geosciences"
}

\author{
Yuichi S. Hayakawa ${ }^{1 *}$, Thad A. Wasklewicz ${ }^{2}$, Hiroyuki Obanawa ${ }^{3}$ and Shigekazu Kusumoto ${ }^{4}$
}

\section{Preface}

Recent technological developments in high-definition data collection of earth surface topography and geophysical properties have led to advances in measuring earth surface processes and dynamics. Here, the term "high definition" includes but does not infer "high resolution." Higher resolution data often provides more detailed information. However, high-resolution data might also introduce more noise, capture denser information than is required to represent a feature and/or its $4 \mathrm{D}$ properties, or may inhibit the explanation of a phenomenon at larger scales. There are also locations currently being explored where high-resolution data collection is not possible yet because the technology does not exist. For example, the ability to obtain even low-resolution bathymetric data in previously inaccessible areas, like deep oceanic and lacustrine environments, can be innovative and reveal unknown features. Therefore, "high-definition data" may comprise a range of resolutions. High-definition data are those data that lead scientists to new analyses of the Earth's surface and permit novel findings that advance the geosciences. Applications of high-definition or high-resolution data are often found in both temporal and spatial contexts, such as chronology (Ishizawa et al. 2017), palaeoenvironments (Landais et al. 2015), meteorology (Harris et al. 2014; Ushio et al. 2015), subsurface geology (Cella and Fedi 2015; Ito et al. 2018), and surface morphology (Oguchi et al. 2013; Tarolli 2014). The theory, acquisition, processing, modeling, and analysis of high-definition data are progressing rapidly in geosciences (Passalacqua et al. 2015). Furthermore, there is increasing demand for well-documented datasets and open-source tools, which are crucial for further advances in science and the instrumentation.

\footnotetext{
* Correspondence: hayakawa@csis.u-tokyo.ac.jp

${ }^{1}$ Faculty of Environmental Earth Science, Hokkaido University, N10W5 Kita-ku, Sapporo, Hokkaido 060-0810, Japan

Full list of author information is available at the end of the article
}

This SPEPS (SPecial call for Excellent Papers on hot topicS) contains seven research papers that are invited as the state-of-the-art articles in the use of high-definition topographic and geophysical data. Several of these articles were presented in the thematic session of the Japanese Geoscience Union annual meeting of 2017. The session was dedicated to the applications of high-definition topographic and geophysical data in a range of geosciences, and the main objective of the present special issue is a wide description of innovative research on high-definition topographic and geophysical data for both the technical issues and geoscientific applications. Various sensors are used in the methodologies, including laser scanning, SfM-MVS (structure-from-motion multi-view stereo) photogrammetry, GNSS (global navigation satellite system) positioning, SAR (synthetic aperture radar) interferometry, gravity, and electromagnetic sensors, based on terrestrial, aerial, or aquatic platforms. Some of the representative ones are terrestrial laser scanning (TLS), unmanned aerial system (UAS), and subsurface geophysical measurements. TLS and UAS provide high-density point clouds of land surface, whose data are often utilized in the form of digital elevation model (DEM) or digital surface model (DSM). Geophysical approaches, including gravity measurements with a higher resolution, can be applied to reveal detailed underground structures which are invisible from the surface. The topics of the papers range from theoretical examinations to practical applications.

Wasklewicz et al. (2017) proposed a theoretical framework of the uncertainty estimation for various sensor measurements of topographic data, including conventional low-resolution DEMs and high-resolution laser scanning or photogrammetric datasets. The work was specifically designed to increase the capability of topographic change detection using different sources of topographic data by evaluating theoretical and actual errors over space and time. The findings highlight the strong 
potential for the use of legacy datasets in detecting long-term topographic changes.

Recent landscape changes can also be captured via high-definition platforms, such as TLS and UAS to produce new insights into landscape evolution in area experiencing seismic activity. TLS was used to detect subtle ground displacement at a centimeter scale in a mud volcano (Hayakawa et al. 2017). An active mud volcano often reacts to a large seismic shake with its surface uplift, but the authors revealed that the mud volcano also actively "breathe" with frequent uplift and subsidence even when no shake is present in the region. Such temporal variations in the mud volcano activities will be further explored with subsurface information to reveal its detailed structure and mechanisms. Saito et al. (2018) explored the topographic changes of landslide-prone areas with a particular emphasis on the effects of a severe earthquake, using high-definition topographic data derived from UASphotogrammetry. They found landslides triggered by the earthquake are much deeper when compared to those caused by heavy rainfall. The difference likely reflects the amplification of seismic acceleration in relationship to the topographic conditions.

Another advantage of the high-definition topographic data obtained by TLS and UAS-photogrammetry is the capability of analyses by the 3D structure of landscapes. Obanawa and Hayakawa (2018) quantified the volume of $3 \mathrm{D}$ polygons representing changed portions in coastal bedrock cliffs, based on the 3D point clouds taken by both TLS and UAS-SfM photogrammetry. The timing and volume of the eroded rock mass were recorded, and possible causal mechanisms, such as oceanic wave attacks and earthquakes, were explored to provide a deeper understanding of this dynamic environment. The findings indicate the wave attacks are more effective in triggering rockfalls than earthquakes, while the other factors including gradual weakening of rock strength by weathering may also affect the stochastic erosion.

Photogrammetric approaches designed to acquire high-definition topographic data are quick and versatile. Gomez and Purdie (2018) demonstrated the capability of quick hazard assessments using high-definition topographic data derived from photogrammetry of aerial images. The images were taken from a UAS and a manned helicopter in rockfall-prone areas in New Zealand, where rapidly degrading glaciers cause the severe conditions of mountain slopes despite the presence of attractive hiking tracks. They showed that a quick data acquisition and rough estimates by simple simulation are critical to protecting people visiting such spectacular, but potentially dangerous natural areas.

The objects of topographic measurement are not only on terrestrial surfaces, but also can be identified for aquatic and subsurface areas. Yamasaki et al. (2017) proposed a novel way to acquire the morphological data of subaqueous sediment surface using a low-cost portable sonar initially designed for the detection of fish. An acoustic approach was demonstrated for a lake bottom mound likely caused by landslides. As an application of high-definition geophysical data, Kusumoto (2017) derived the gravity gradient tensor from dense gravity survey data carried out along a profile and estimated the dip angle of a fault in a sedimentary basin using its eigenvector. The author concludes this is a practical method to estimate the fault dip from gravity anomalies from high-definition gravity measurements.

The papers presented in this special issue are only a part of the growing field of the high-definition data acquisition and applications, but each study shows advances to the field of geoscience. The advances, in conjunction with the free access to the special issue articles in this open journal, provide a valuable outlet to increasing demand to share such high-definition geoscientific data in an open platform. The PEPS platform provides an integral international venue to achieve the transfer of cutting-edge knowledge on a variety of topics of relevance to the broader Earth science community. The diversity of topics covered in this issue and others should appeal to researchers trying to piece together the heterogeneous nature environmental change across our planet and others.

\section{Funding}

This work was supported by JSPS KAKENHI Grant Numbers JP17H02031 and JP16KK0012.

Authors' contributions

All authors wrote and approved this final manuscript.

\section{Competing interests}

The authors declare that they have no competing interests.

\section{Publisher's Note}

Springer Nature remains neutral with regard to jurisdictional claims in published maps and institutional affiliations.

\section{Author details}

${ }^{1}$ Faculty of Environmental Earth Science, Hokkaido University, N10W5 Kita-ku, Sapporo, Hokkaido 060-0810, Japan. ²Department of Geography, Planning and Environment, East Carolina University, Brewster Building A227, Greenville, NC 27858, USA. ${ }^{3}$ Hokkaido Agricultural Research Center, National Agriculture and Food Research Organization, 1 Hitsujigaoka, Toyohira-ku, Sapporo, Hokkaido 062-8555, Japan. ${ }^{4}$ Graduate School of Science and Engineering for Research, University of Toyama, 3910 Gofuku, Toyama 930-8555, Japan.

Received: 26 November 2018 Accepted: 26 November 2018 Published online: 24 December 2018

\section{References}

Cella F, Fedi M (2015) High-resolution geophysical 3D imaging for archaeology by magnetic and EM data: the case of the Iron age settlement of Torre Galli, Southern Italy. Surv Geophys 36:831-850. https://doi.org/10.1007/s10712-0159341-3

Gomez C, Purdie H (2018) Point cloud technology and 2D computational flow dynamic modeling for rapid hazards and disaster risk appraisal on Yellow Creek fan, Southern Alps of New Zealand. Prog Earth Planet Sci 5:50. https:// doi.org/10.1186/s40645-018-0208-3 
Harris I, Jones PD, Osborn TJ, Lister DH (2014) Updated high-resolution grids of monthly climatic observations - the CRU TS3.10 dataset. Int J Climatol 34: 623-642. https://doi.org/10.1002/joc.3711

Hayakawa YS, Kusumoto S, Matta N (2017) Seismic and inter-seismic ground surface deformations of the Murono mud volcano (central Japan): a laser scanning approach. Prog Earth Planet Sci 4:3. https://doi.org/10.1186/s40645016-0116-3

Ishizawa T, Goto K, Yokoyama Y et al (2017) Sequential radiocarbon measurement of bulk peat for high-precision dating of tsunami deposits. Quat Geochronol 41:202-210. https://doi.org/10.1016/j.quageo.2017.05.003

Ito Y, Oguchi T, Masuda F (2018) Late Quaternary depositional sequences and landforms in relation to sea-level changes in the Osaka intra-arc basin, Japan: a borehole database analysis. Quat Int 471:298-317. https://doi.org/10.1016/j. quaint.2017.09.031

Kusumoto S (2017) Eigenvector of gravity gradient tensor for estimating fault dips considering fault type. Prog Earth Planet Sci 4:15. https://doi.org/10. 1186/s40645-017-0130-0

Landais A, Masson-Delmotte V, Stenni B et al (2015) A review of the bipolar seesaw from synchronized and high resolution ice core water stable isotope records from Greenland and East Antarctica. Quat Sci Rev 114:18e32-18e32. https://doi.org/10.1016/.qquascirev.2015.01.031

Obanawa H, Hayakawa YS (2018) Variations in volumetric erosion rates of bedrock cliffs on a small inaccessible coastal island determined using measurements by an unmanned aerial vehicle with structure-from-motion and terrestrial laser scanning. Prog Earth Planet Sci. https://doi.org/10.1186/ s40645-018-0191-8

Oguchi T, Wasklewicz T, Hayakawa YS (2013) Remote data in fluvial geomorphology: characteristics and applications. In: Shroder J, Wohl E (eds) Treatise on geomorphology. Academic press, Elsevier, San Diego, pp 711-729

Passalacqua P, Belmont P, Staley DM et al (2015) Analyzing high resolution topography for advancing the understanding of mass and energy transfer through landscapes: a review. Earth-Science Rev 148:174-193. https://doi.org/ 10.1016/j.earscirev.2015.05.012

Saito H, Uchiyama S, Hayakawa YS, Obanawa H (2018) Landslides triggered by an earthquake and heavy rainfalls at Aso volcano, Japan, detected by UAS and SfM-MVS photogrammetry. Prog Earth Planet Sci. https://doi.org/10.1186/ s40645-018-0169-6

Tarolli P (2014) High-resolution topography for understanding Earth surface processes: opportunities and challenges. Geomorphology 216:295-312. https://doi.org/10.1016/j.geomorph.2014.03.008

Ushio T, Wu T, Yoshida S (2015) Review of recent progress in lightning and thunderstorm detection techniques in Asia. Atmos Res 154:89-102. https:/ doi.org/10.1016/j.atmosres.2014.10.001

Wasklewicz T, Zhu Z, Gares P (2017) Simulating and quantifying legacy topographic data uncertainty: an initial step to advancing topographic change analyses. Prog Earth Planet Sci 4:32. https://doi.org/10.1186/s40645017-0144-7

Yamasaki S, Tabusa T, Iwasaki S, Hiramatsu M (2017) Acoustic water bottom investigation with a remotely operated watercraft survey system. Prog Earth Planet Sci 4:25. https://doi.org/10.1186/s40645-017-0140-y

\section{Submit your manuscript to a SpringerOpen ${ }^{\circ}$ journal and benefit from:}

- Convenient online submission

- Rigorous peer review

- Open access: articles freely available online

- High visibility within the field

- Retaining the copyright to your article

Submit your next manuscript at $\boldsymbol{\nabla}$ springeropen.com 